\title{
Inducible Presynaptic Glutamine Transport Supports Glutamatergic Transmission at the Calyx of Held Synapse
}

\author{
Daniela Billups, ${ }^{\star}$ Mari-Carmen Marx, ${ }^{\star}$ Ioanna Mela, and Brian Billups \\ Department of Pharmacology, University of Cambridge, Cambridge CB2 1PD, United Kingdom
}

The mechanisms by which the excitatory neurotransmitter glutamate is recycled at synapses are currently unknown. By examining the functional expression of plasma membrane transporters at presynaptic terminals, we aim to elucidate some of the mechanisms of glutamate recycling. Using whole-cell voltage-clamp recordings from rat calyx of Held presynaptic terminals, our data show, for the first time, that the glutamate precursor glutamine causes the direct activation of an electrogenic, sodium-dependent presynaptic transporter, which supplies glutamine for generation of presynaptic glutamate and helps sustain synaptic transmission. Interestingly, the functional expression of this transporter at the presynaptic plasma membrane is dynamically controlled by electrical activity of the terminal, indicating that uptake of neurotransmitter precursors is controlled by the demand at an individual terminal. Induction of the transporter current is calcium-dependent and inhibited by botulinum neurotoxin $\mathrm{C}$, demonstrating the involvement of SNARE-dependent exocytosis in inserting transporters into the plasma membrane when the terminal is active. Conversely, inactivity of the presynaptic terminal results in removal of transporters via clathrin-mediated endocytosis. To investigate whether the presynaptic glutamine transporter supplies the precursor for generating the synaptically released glutamate, we measured miniature EPSCs to assess vesicular glutamate content. When the presynaptic glutamate pool was turned over by synaptic activity, inhibiting the presynaptic glutamine transporters with MeAIB reduced the miniature EPSC amplitude significantly. This demonstrates that presynaptic glutamine transport is centrally involved in the production of glutamate and assists in maintaining excitatory neurotransmission.

\section{Introduction}

Glutamatergic presynaptic terminals rely on the supply of precursor molecules to regenerate their supply of neurotransmitters. However, the nature of the supply mechanism and the molecules that are taken up by the presynaptic terminal are not known. Radiotracing studies suggest that released glutamate is sequestered by astrocytes, which is then converted into glutamine and transported back to the presynaptic terminal where it acts as a precursor for glutamate, forming a glutamate-glutamine cycle (Sibson et al., 2001). However, the physiological importance of this cycle is controversial. Although neurotransmission between cultured hippocampal neurons can continue in the absence of glutamine or glia (Kam and Nicoll, 2007), it is clear that synaptic transmission in active neocortical brain slices does rely on the supply of external glutamine from glia (Tani et al., 2010). The glutamate transporters responsible for the uptake of glutamate into glia have been identified as members of the high-affinity

\footnotetext{
Received April 5, 2013; revised Sept. 3, 2013; accepted Sept. 29, 2013.

Author contributions:D.B.,M.-C.M., and B.B. designed research; D.B., M.-C.M., I.M., and B.B. performed research; D.B., M.-C.M., and B.B. analyzed data; D.B., M.-C.M., and B.B. wrote the paper.

This work was supported by The Royal Society. We thank Prof. Giampietro Schiavo (Cancer Research United Kingdom, London) for the botulinum neurotoxin ( plasmid and Prof. J. Michael Edwardson (University of Cambridge, United Kingdom) for assisting in toxin preparation.

The authors declare no competing financial interests.

${ }^{*}$ D.B. and M.-C.M. contributed equally to this work.

Correspondence should be addressed to Dr. Brian Billups, Department of Pharmacology, University of Cambridge, Tennis Court Road, Cambridge CB2 1PD, United Kingdom. E-mail: bjb41@cam.ac.uk.

DOI:10.1523/JNEUROSCI.1466-13.2013

Copyright $\odot 2013$ the authors $\quad 0270-6474 / 13 / 3317429-06 \$ 15.00 / 0$
}

excitatory amino acid transporter (EAAT) family. However, the nature of the transporters that mediate the translocation of glutamine from glia to presynaptic terminals has not been established. The aim of this study is to demonstrate the presence of glutamine transporters on glutamatergic presynaptic terminals and to evaluate their contribution to sustaining the presynaptic glutamate supply to maintain excitatory neurotransmission.

We have studied the expression of functional glutamine transporters using electrophysiological recordings from the calyx of Held presynaptic terminal. This glutamatergic terminal contacts the soma of the principal cells of the medial nucleus of the trapezoid body (MNTB) in the auditory brainstem. It is large enough to be whole-cell patch-clamped and hence is one of the most comprehensively studied synapses in the mammalian CNS (Schneggenburger and Forsythe, 2006). We have recently shown that astrocytes immediately adjacent to this synapse release glutamine in response to EAAT activation (Uwechue et al., 2012), with tight temporal coupling that suggests that the glutamate-glutamine cycle may function to replenish the presynaptic glutamate supply on a rapid time-scale. We hypothesized that glutamine activates electrogenic presynaptic transporters, which would be evident as a membrane current in voltage-clamped calyces of Held. Here we show that glutamine transporters are functional in the presynaptic terminal and that their plasma membrane expression is dynamically controlled by presynaptic activity. Moreover, by measuring the miniature EPSC (mEPSC) amplitude in the MNTB neurons, we also demonstrate that these transporters contribute to maintaining the efficacy of synaptic transmission. 


\section{Materials and Methods}

Brain slice recording. Brainstem slices (120-180 $\mu \mathrm{m}$ thick) containing MNTB were obtained from 10-15 day-old Wistar rats of either sex, and whole-cell patch-clamp recordings performed as previously described (Blot et al., 2009). Whole-cell series resistances were $<20 \mathrm{M} \Omega$ and compensated $>70 \%$. Synaptic activity was stimulated with a bipolar platinum electrode placed at the midline. MNTB neurons with active presynaptic connections were detected by fura-2 calcium imaging before patch-clamp recording, as previously described (Billups et al., 2002).

Experimental solutions. Experiments were performed at physiological temperature $\left(34-36^{\circ} \mathrm{C}\right)$ in a solution containing the following (in $\mathrm{mM}$ ): 125 $\mathrm{NaCl}, 2.5 \mathrm{KCl}, 10$ glucose, $1.25 \mathrm{NaH}_{2} \mathrm{PO}_{4}, 26 \mathrm{NaHCO}_{3}, 1 \mathrm{MgCl}_{2}, 2 \mathrm{CaCl}_{2}$, 0.01 ( -)-bicuculline methochloride, and 0.001 strychnine; gassed with $95 \%$ $\mathrm{O}_{2} / 5 \% \mathrm{CO}_{2}, \mathrm{pH}$ 7.4. For presynaptic recordings, the following antagonists were added (in $\mu \mathrm{M}$ ): 40 DL-2-amino-5-phospohonopentanoic acid, 10 dizocilpine maleate (MK801), 20 NBQX, 1 TTX, and 10 mM tetraethylammonium chloride (TEA). The internal patch-pipette solution for presynaptic recordings contained the following (in $\mathrm{mM}$ ): 110 cesium methanesulfonate, 40 HEPES, 10 TEA-Cl, 2 Mg-ATP, $0.5 \mathrm{Na}$-GTP, $0.008 \mathrm{CaCl}_{2}, 0.2$ EGTA, 20 sucrose, and $<0.05 \%$ Lucifer yellow ( $\mathrm{pH} 7.2$ with $\mathrm{CsOH}$ ). For postsynaptic recordings, ATP, GTP, and $\mathrm{CaCl}_{2}$ were omitted and 1 mM EGTA and 1 mM QX314 were included. Transporter substrates (L-glutamate and L-glutamine) were dissolved in the external solution and applied by pressurized ejection (2-8 psi) from pipettes (open tip resistance 4-6 M $\Omega$ ) using a Picospritzer II (General Valve). For caged calcium experiments, the internal solution contained (in mM) 110 cesium methanesulfonate, 40 HEPES, 10 TEA-Cl, 20 sucrose, $2 \mathrm{Na}_{2}$-ATP, $0.5 \mathrm{Na}-\mathrm{GTP}, 0.25 \mathrm{CaCl}_{2}, 3$ 1-(4,5dimethoxy-2-nitrophenyl)-1,2-diaminoethane- $\mathrm{N}, \mathrm{N}, \mathrm{N}^{\prime}, \mathrm{N}^{\prime}$-tetraacetic acid (DMNP-EDTA), and 0.1 fura-FF. Calcium was released by a $0.5 \mathrm{~ms}$ flash from a Xe lamp (360 $\pm 40 \mathrm{~nm}$; Rapp OptoElectronic), delivered $2 \mathrm{~s}$ before each glutamine puff. DL-2-Amino-5-phospohonopentanoic acid, MK801, bicuculline, strychnine, NBQX, TTX, and Pitstop-1 were obtained from Abcam Biochemicals; DMNP-EDTA was obtained from Synaptic Systems; DLthreo- $\beta$-benzyloxyaspartic acid (TBOA) was purchased from R\&D Systems. All other chemicals were acquired from Sigma-Aldrich.

Preparation of botulinum neurotoxin C (BoNT/C) light chain. BoNT/C light chain bearing a C-terminal His6 epitope tag, in the vector pQE3 (QIAGEN), was expressed in Escherichia coli and purified by binding to $\mathrm{Ni}^{2+}$-agarose (Probond; Invitrogen) followed by elution with imidazole. Toxin was dialyzed against internal patch-pipette solution, and protein purity was checked by SDS-PAGE followed by Coomassie Blue staining. Patch pipettes were tip-filled with BoNT/C-free internal solution and back-filled with internal solution containing $0.5 \mu \mathrm{M}$ BoNT/C. Heat inactivated BoNT/C $\left(95^{\circ} \mathrm{C} ; 7 \mathrm{~min}\right)$ was used as a control.

Data analysis. Data are presented as mean \pm SEM and regarded as statistically significant when $p<0.05$ using one-way ANOVA with Dunnett's post hoc test (GraphPad Prism 6.01; GraphPad Software).

\section{Results}

To investigate the activity of functional transporters in presynaptic terminals, calyces of Held in brainstem slices were whole-cell voltage-clamped at $-80 \mathrm{mV}$ and visually identified by the fluorescent dye Lucifer yellow, included in the internal solution. Presynaptic transporters were activated by puff application of substrates from pipettes placed $20-50 \mu \mathrm{m}$ away from the presynaptic terminal (Fig. 1A). Application of $200 \mu \mathrm{M}$ glutamate for $5 \mathrm{~s}$ failed to elicit a membrane current in presynaptic terminals (Fig. $1 B ; 0.2 \pm 0.4 \mathrm{pA} ; n=3$ ), demonstrating a lack of direct presynaptic glutamate transport via EAATs. Glutamine (10 mM) also failed to generate a membrane current when initially applied to the same terminals (Fig. $1 B ;-0.7 \pm 0.4 \mathrm{pA} ; n=17$ ). However, after brief depolarization of the presynaptic terminal, a glutamineevoked current $\left(\mathrm{I}_{\mathrm{Gln}}\right)$ became apparent. To induce $\mathrm{I}_{\mathrm{Gln}}$, terminals were stimulated by trains of depolarization $(-80$ to $0 \mathrm{mV}$ for 2 $\mathrm{ms}$, repeated at $100 \mathrm{~Hz}$ for $2 \mathrm{~s}$ ). This protocol activates presynaptic P-type calcium channels and causes vesicular exocytosis from the terminals (Billups and Forsythe, 2002). These trains were repeated every $30 \mathrm{~s}$, immediately before the glutamine puffs. Within 1-3 trains, $\mathrm{I}_{\mathrm{Gln}}$ was fully established, attaining a magnitude of $-15.8 \pm 1.4 \mathrm{pA}$ (Fig. $1 C ; n=27$ ). Longer constant depolarizations ( -80 to $0 \mathrm{mV}$ for $5 \mathrm{~s}$ ) were equally effective at inducing $\mathrm{I}_{\mathrm{Gln}}(-15.1 \pm 1.4 \mathrm{pA} ; n=14$; data not shown). Despite the induction of $\mathrm{I}_{\mathrm{Gln}}$ by stimulation, glutamate still did not generate an EAAT current, even after stimulation $(-0.01 \pm 0.52 \mathrm{pA}$; $n=3$; Fig. $1 B$ ). Additionally, replacing methansulfonate with $\mathrm{NO}_{3}^{-}$in the internal solution to enhance EAAT currents (Palmer et al., 2003) did not reveal a glutamate-induced response $(-0.1 \pm$ $0.3 \mathrm{pA} ; n=3)$, arguing against a role for direct presynaptic glutamate uptake in glutamate recycling. Stopping the stimulation trains before the glutamine puffs caused $\mathrm{I}_{\mathrm{Gln}}$ to rapidly decline, with a half-time of $<30 \mathrm{~s}$. A subsequent bout of stimulation caused $\mathrm{I}_{\mathrm{Gln}}$ to swiftly return (Fig. 1C), indicating a dynamic induction of $\mathrm{I}_{\mathrm{Gln}}$ by electrical activity, that is rapid and reversible.

What is the mechanism of this current induction? We hypothesized that electrical stimulation causes the insertion of glutamine transporters into the presynaptic plasma membrane via a mechanism involving $\mathrm{Ca}^{2+}$-dependent vesicle exocytosis. To investigate this hypothesis, we omitted $\mathrm{Ca}^{2+}$ from the external solution midway through the experiment, after the induction of $\mathrm{I}_{\mathrm{Gln}}$ by depolarization. This caused $\mathrm{I}_{\mathrm{Gln}}$ to rapidly decline to $-1.6 \pm$ 0.9 pA (inhibited by $93 \pm 3 \% ; n=3 ; p<0.001$ ), in a manner similar to stopping the stimulation (Fig. $1 D$ ). Moreover, photorelease of caged presynaptic calcium, in the absence of any electrical stimulation, also induced $\mathrm{I}_{\mathrm{Gln}}$ to the same magnitude (Fig. $1 D ;-12.4 \pm 2.3 \mathrm{pA} ; n=4 ; p>0.05)$. These data demonstrate that calcium is necessary and sufficient for the induction of $\mathrm{I}_{\mathrm{Gln}}$. To further test the vesicle insertion theory, BoNT/C was included in the patch pipette to cleave syntaxin and SNAP-25 and thus inhibit exocytosis (Sakaba et al., 2005). BoNT/C caused a decline of $\mathrm{I}_{\mathrm{Gln}}$ as it diffused into the terminal from the pipette. After whole-cell recording for at least $15 \mathrm{~min}, \mathrm{I}_{\mathrm{Gln}}$ was inhibited by $61 \pm 6 \%$ (Fig. $1 D ; n=3 ; p<0.01$ ) by BoNT/C, with no change of the presynaptic calcium current magnitude (1.2 $\pm 0.4 \mathrm{nA}$ in control and $1.3 \pm 0.2 \mathrm{pA}$ in BoNT/C; $p>0.05)$. As a control, heat inactivated BoNT/C had no effect on $\mathrm{I}_{\mathrm{Gln}}$ induction $(-19.3 \pm 0.9$ $\mathrm{pA} ; n=4 ; p>0.05)$. These data demonstrate the involvement of SNARE-dependent exocytosis in the induction of $\mathrm{I}_{\mathrm{Gln}}$. Additionally, inclusion of $200 \mu \mathrm{M}$ Pitstop-1 (von Kleist et al., 2011) in the internal solution prevented $\mathrm{I}_{\mathrm{Gln}}$ declining when presynaptic stimulation was stopped (Fig. $1 C, D ;-12.1 \pm 0.6 \mathrm{pA} ; n=4 ; p>0.05$ ), implicating clathrin-mediated endocytosis in reversing $\mathrm{I}_{\mathrm{Gln}}$ induction.

We next investigated the underlying process that mediates $\mathrm{I}_{\mathrm{Gln}}$. After induction of $\mathrm{I}_{\mathrm{Gln}}$, bath application of the glutamine transporter substrate inhibitor $\alpha$-(methylamino)isobutyric acid (MeAIB; $20 \mathrm{~mm}$ ) rapidly reduced the current to $-0.8 \pm 0.3 \mathrm{pA}$ (Fig. 2A), representing a $94 \pm 3 \%$ inhibition (Fig. $2 A-C ; n=3$; $p<0.001)$. In addition, removal of external $\mathrm{Na}^{+}$abolished $\mathrm{I}_{\mathrm{Gln}}$ (reduced by $99 \pm 1 \% ; n=3 ; p<0.001$; Fig. $2 B$ ). In contrast, the EAAT inhibitor TBOA $(200 \mu \mathrm{M})$ and EAAT substrate D-aspartate ( $1 \mathrm{~mm}$ ) had no effect on $\mathrm{I}_{\mathrm{Gln}}$ (Fig. $2 B ; n=3 ; p>0.05$ in both cases), demonstrating a lack of involvement of these transporters in generating $\mathrm{I}_{\mathrm{Gln}}$. As membrane transporter currents elicited by the external application of a substrate are not expected to show reversal at positive membrane potentials, we investigated the current-voltage relationship of the induced $\mathrm{I}_{\mathrm{Gln}}$. Depolarization of the presynaptic terminal reduced $\mathrm{I}_{\mathrm{Gln}}$ with the current at $+40 \mathrm{mV}$ being $36 \pm 10 \%(n=3)$ of that at $-80 \mathrm{mV}$. Significantly though, it does not show reversal (Fig. 2D). These data are consistent with 
A

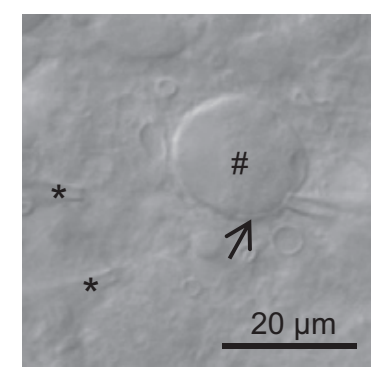

C
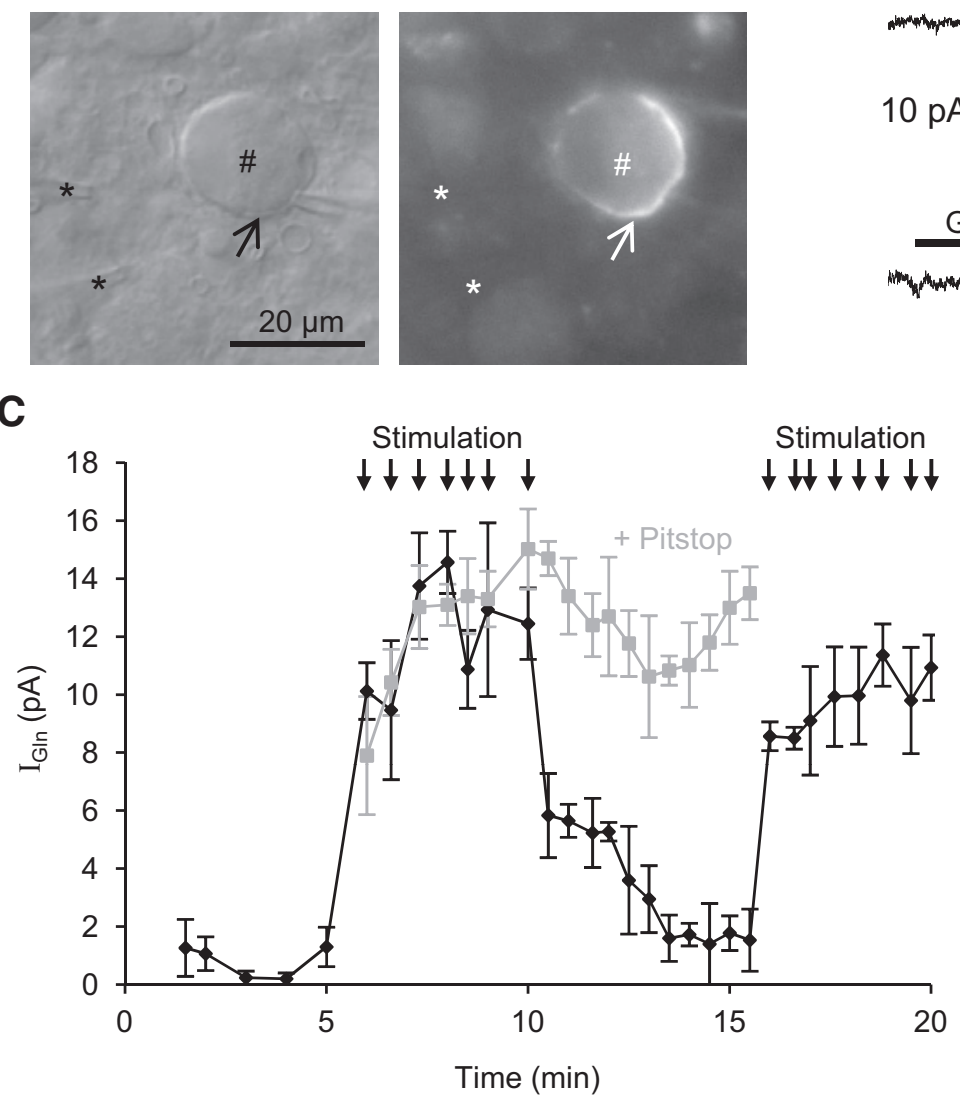

B
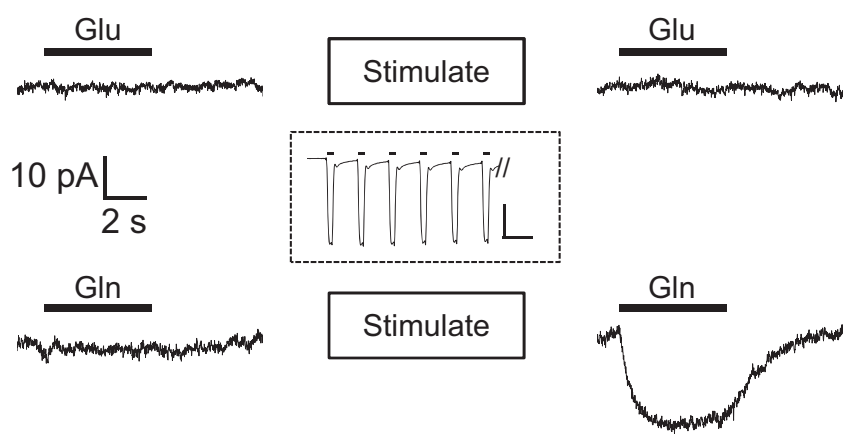

D

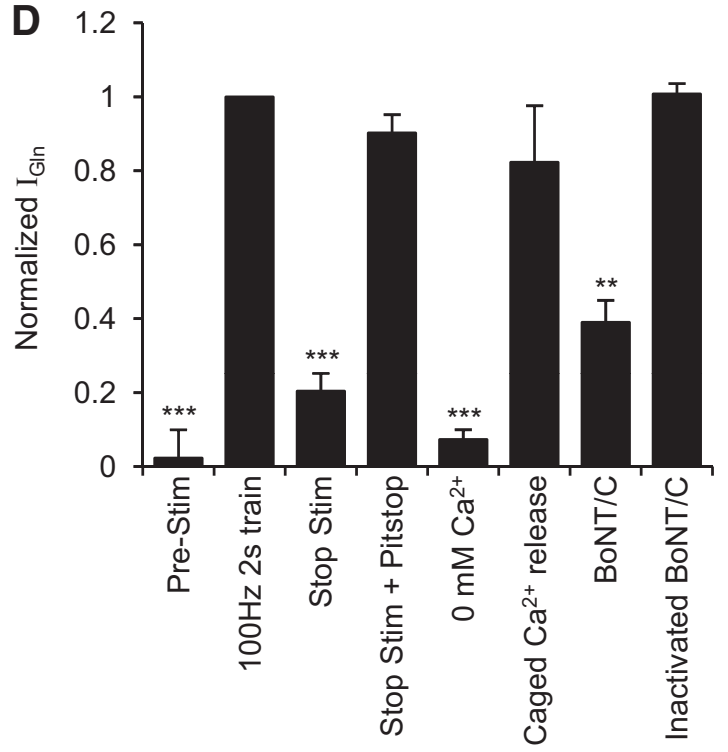

Figure 1. Membrane depolarization rapidly and reversibly induces a calcium and exocytosis-dependent glutamine-mediated current in presynaptic terminals. $\boldsymbol{A}$, A differential interference contrast image and the corresponding fluorescence image of a Lucifer yellow-filled calyx of Held presynaptic terminal (arrow) surrounding an MNTB neuron (\#) in a brainstem slice. Glutamine (10 $\mathrm{mm})$ or glutamate $(200 \mu \mathrm{m})$ was applied by pressure ejection from one of two puffer pipettes $\left(^{*}\right)$ placed equidistant from the terminal. $\boldsymbol{B}$, The $5 \mathrm{~s}$ puff application of glutamate did not elicit a membrane current before or after activation of $\mathrm{Ca}^{2+}$ channels by depolarization trains (inset; (alibration: $1 \mathrm{nA}, 10 \mathrm{~ms}$ ). Glutamine induced a membrane current after $\mathbf{C a}{ }^{2+}$-channel activation. $\boldsymbol{C}$, The magnitude of $\mathrm{I}_{\mathrm{GIn}}$ over time in control (black trace) and with Pitstop- 1 in the patch pipette (gray trace). Stimulation of the presynaptic calcium channels was performed before each puff application, as indicated by the arrows. $D$, Averaged data showing $\mathrm{I}_{\mathrm{Gln}}$ induced by stimulation of presynaptic $\mathrm{Ca}^{2+}$ currents or release of caged calcium in the presynaptic terminal. Induction was reversed by cessation of stimulation, by the removal of external $\mathrm{Ca}^{2+}$, or by the inclusion of BoNT/C in the patch-pipette. Reversal of induction was prevented by Pitstop-1. ${ }^{* *} p<0.01$. ${ }^{* *} p<0.001$.

$\mathrm{I}_{\mathrm{Gln}}$ being mediated by a $\mathrm{Na}^{+}$-dependent electrogenic membrane transporter.

To explore the role that presynaptic glutamine transport plays in sustaining the glutamate supply for fast excitatory transmission, we investigated the vesicular glutamate content by recording glutamatergic mEPSCs. The principal cells of the MNTB, which are postsynaptic to the calyx of Held terminal, were wholecell voltage-clamped at $-70 \mathrm{mV}$ and synaptic currents recorded. To mimic physiological levels of activity, the calyx of Held synapse was continuously stimulated at $200 \mathrm{~Hz}$ to exocytose vesicles and promote turnover of the presynaptic glutamate pool. This stimulation was interrupted for $15 \mathrm{~s}$ each minute to record mEPSCs and check series resistance compensation. Inhibition of presynaptic glutamine transport by the application of $20 \mathrm{~mm}$ MeAIB had little effect for 3-4 min but caused a decline in mEPSC amplitude over the next $10 \mathrm{~min}$ (Fig. 3A). The mEPSC amplitude was reduced from $-38.8 \pm 3.5 \mathrm{pA}$ to $-28.6 \pm 3.4 \mathrm{pA}$ by MeAIB (Fig. 3; a $26 \pm 4 \%$ reduction; $n=5$ cells; $p<0.05$ ), indicating that presynaptic glutamate supply is partially dependent on glutamine transport. Under identical conditions, mEPSC amplitudes were stable in the absence of MeAIB (Fig. $3 A, B ; 102 \pm 4 \% ; n=5 ; p>$ $0.05)$. To ensure that MeAIB does not have unwanted effects on other aspects of synaptic transmission, such as presynaptic cal- cium channels or postsynaptic AMPA receptors, mEPSCs were recorded from MNTB neurons at a stimulation frequency of 0.1 $\mathrm{Hz}$. At this low frequency, the presynaptic glutamate pool is not depleted and the efficacy of neurotransmission is not expected to be dependent upon glutamate recycling via glutamine. Under these conditions, MeAIB had no effect on the magnitude of mEPSCs (Fig. $3 B ; 105 \pm 7 \%$ of control; $n=5 ; p>0.05$ ). Similarly, MeAIB had no effect on EPSCs evoked at $0.1 \mathrm{~Hz}(98 \pm 6 \%$ of control; $n=8 ; p>0.05)$, demonstrating that MeAIB does not have nonspecific effects on synaptic transmission. These data demonstrate that the inhibition of mEPSC amplitude by MeAIB after $200 \mathrm{~Hz}$ stimulation must be a result of reduced vesicular glutamate content.

\section{Discussion}

Our data reveal the first direct recording of functional glutamine transport in individual presynaptic terminals. Intriguingly, this transport is induced by presynaptic activity, and its expression at the plasma membrane is dynamically controlled by a calcium and SNARE-dependent exocytotic mechanism and by clathrinmediated endocytosis. We go on to show that this presynaptic glutamine transport helps to maintain the glutamate supply for neurotransmission at the calyx of Held synapse. 
A
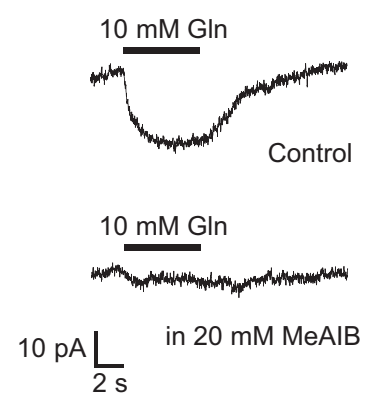

C

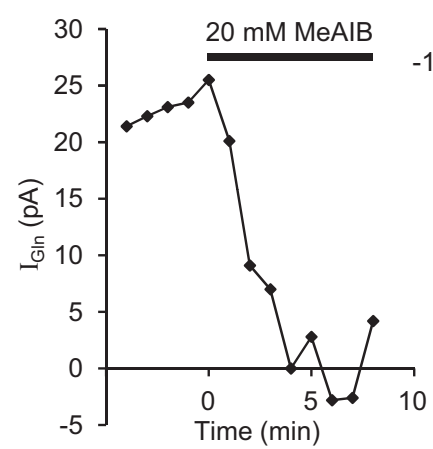

D
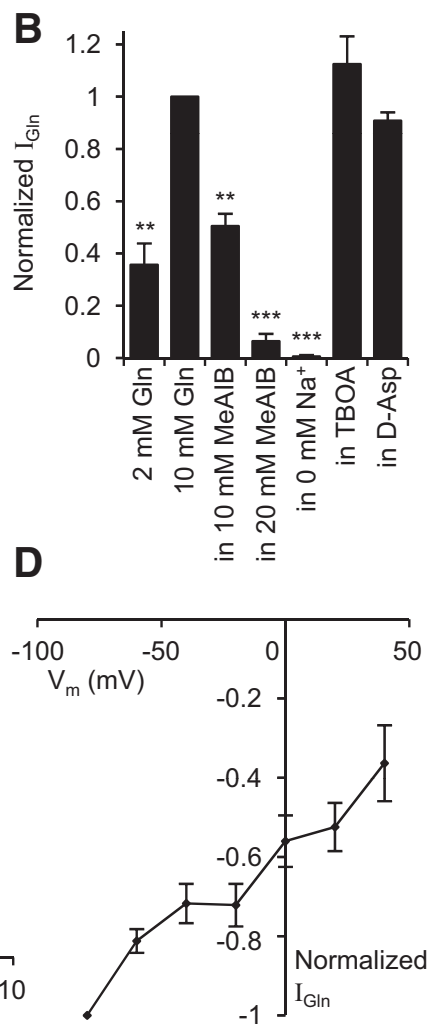

Figure 2. The induced presynaptic glutamine response is mediated by amino acid transporters. $\boldsymbol{A}$, Single-cell representative traces of $5 \mathrm{~s}$ puff application of glutamine $(10 \mathrm{~mm})$ inducing a membrane current that was substantially inhibited by the amino acid transporter substrate MeAIB (20 mm). B, Averaged data show that MeAIB or removal of external $\mathrm{Na}{ }^{+}$eliminates $\mathrm{I}_{\mathrm{Gln}}$ whereas $200 \mu \mathrm{M}$ TBOA or $1 \mathrm{~mm}$ D-aspartate has no effect. ${ }^{* *} p<0.01$. ${ }^{* * *} p<0.001$. $\boldsymbol{C}$, The magnitude of $\mathrm{I}_{\mathrm{Gln}}$ after activation of $\mathrm{Ca}^{2+}$ currents in a single cell as MeAIB is applied in the bath solution and included in the puffer pipette, showing rapid inhibition. $D$, Current-voltage relationship of $\mathrm{I}_{\mathrm{GIn}}$ indicates transporter rather than ion channel activation ( $n \geq 3$ for each voltage).

The induced glutamine-evoked current does not show reversal at positive membrane potentials, which is indicative of transporter rather than ion channel activation. The underlying transporters are electrogenic, sodium-dependent and inhibited by MeAIB. MeAIB is a substrate inhibitor of system A neutral amino acid transporters (Christensen et al., 1965) but also inhibits other electrogenic glutamine transporters, such as members of the broad specificity neutral amino acid transporter $\left(\mathrm{B}^{0} \mathrm{AT}\right)$ family (e.g., NTT4/XT1: SLC6A17; Zaia and Reimer, 2009). Since system A has been identified in presynaptic terminals using immunohistological techniques (Armano et al., 2002; Chaudhry et al., 2002) and NTT4/XT1 has been proposed to be presynaptic and is inserted and removed from the plasma membrane via exocytosis and endocytosis (Zaia and Reimer, 2009), the presynaptic glutamine transport we observe could be mediated by one of these transporters.

The expression of these presynaptic glutamine transporters in the plasma membrane is controlled by the level of neuronal activity, in a highly dynamic way. This indicates that the synapse can exert a substantial degree of control over the neurotransmitter supply, linked to the demand of the system. In vivo, the calyx of Held synapse is continuously active with a spontaneous frequency of up to $\sim 100 \mathrm{~Hz}$ and sound-induced bursts of 200-400 Hz (Sommer et al., 1993; KoppScheinpflug et al., 2008). In brain slices, it can sustain firing at $>500$ $\mathrm{Hz}$ (Taschenberger and von Gersdorff, 2000); however, there is no spontaneous activity as the presynaptic neuronal cell body in the
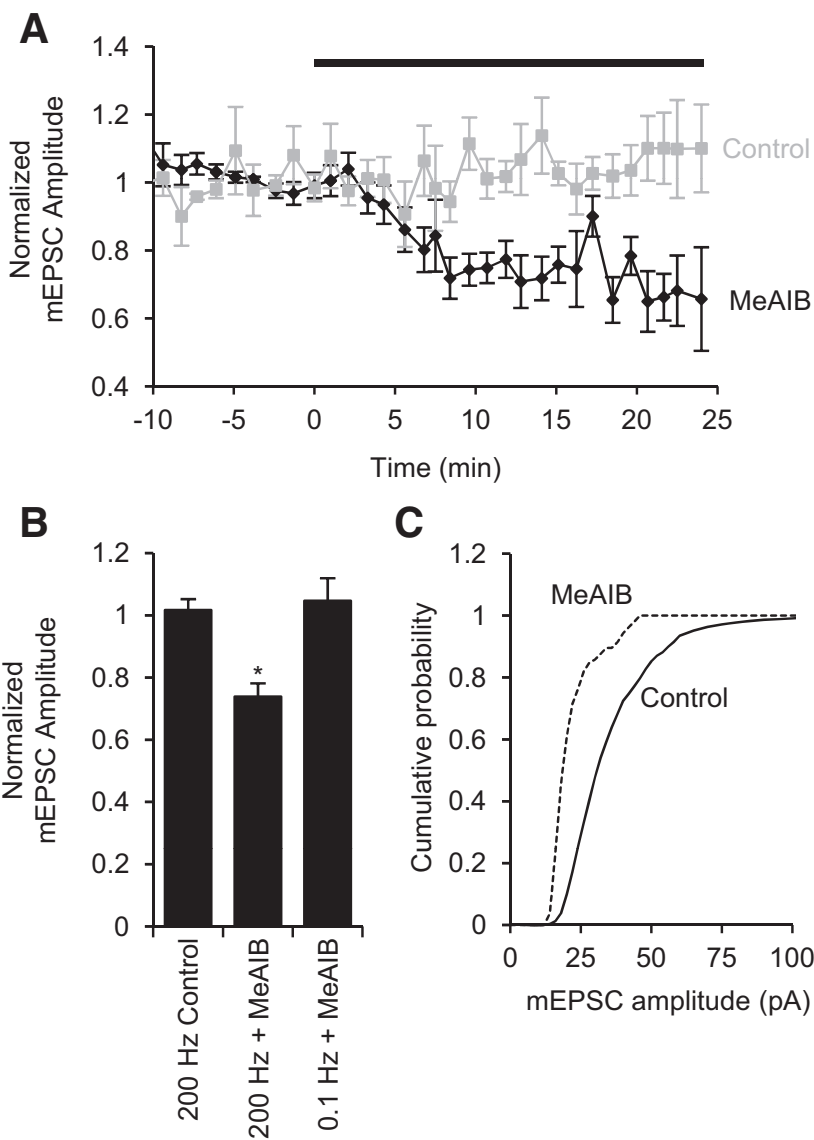

C

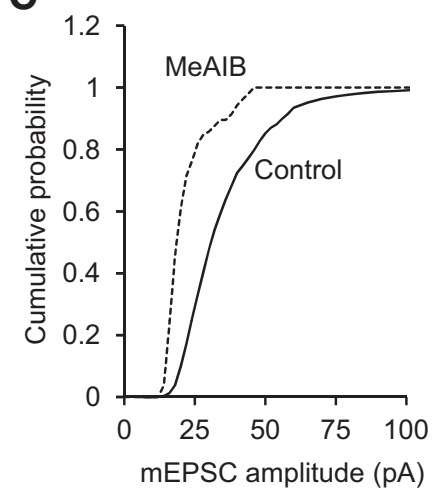

Figure 3. Presynaptic glutamine transport sustains glutamatergic transmission. $\boldsymbol{A}, \mathrm{mEPSC}$ amplitudes recorded from voltage-clamped postsynaptic MNTB principal neurons after stimulation at $200 \mathrm{~Hz}$ to promote turnover of the presynaptic glutamate pool, before and during bath application of $20 \mathrm{~mm}$ MeAIB (application bar, black trace; $n=5$ ) and in control ( $200 \mathrm{~Hz}$ stimulation but no MeAIB; gray trace; $n=5$ ). $\boldsymbol{B}, \mathrm{mEPSC}$ amplitude is significantly inhibited by MeAIB during $200 \mathrm{~Hz}$ stimulation but is not reduced during $0.1 \mathrm{~Hz}$ stimulation. ${ }^{*} p<0.05$. C, Representative graph showing cumulative frequency of mEPSC amplitudes from a single cell stimulated at $200 \mathrm{~Hz}$ before and $10-15$ min after MeAIB application.

contralateral cochlear nucleus is absent. Under these artificially quiescent conditions, the presynaptic transporter currents were not observed. However, stimulation of the terminal to mimic physiological trains of firing resulted in a rapid, calcium-mediated induction of glutamine transporter current. Inhibition of this induction by BoNT/C, which is effective in blocking synaptic vesicle exocytosis at the calyx of Held (Sakaba et al., 2005), suggests that, in response to synaptic activity, vesicles containing transporters are inserted into the presynaptic plasma membrane by a calcium-dependent exocytotic mechanism. The inability of BoNT/C to completely reverse the effect of stimulation on $\mathrm{I}_{\mathrm{Gln}}$ may reflect the incomplete dialysis of the presynaptic cytoplasm with the peptide. The decline in transporter function that is observed when presynaptic stimulation is halted is a result of the internalization of transporters via a clathrin-dependent endocytotic mechanism, as is evident from the effects of Pitstop-1. This regulation of presynaptic transporter plasma membrane expression is similar to that observed for the GAT1 GABA transporter, which is located on small, clear presynaptic vesicles that are subject to exocytosis and endocytosis (Deken et al., 2003). These vesicles are distinct from the neurotransmitter containing vesicles, which may also be the case for the glutamine transporter containing vesicles that we have detected. The rapid induction and tight temporal coupling between electrical activity and transporter function that we observe 
represent a novel form of homeostatic short-term plasticity of synaptic function.

We propose that presynaptic transporters supply glutamine for the production of glutamate to sustain neurotransmission. If this is the case, the magnitude of $\mathrm{I}_{\mathrm{Gln}}$ should reflect the amount of glutamine needed to produce enough glutamate to match that released by synaptic transmission. The glutamine transport current we observe $(-15.8 \pm 1.4 \mathrm{pA})$ would supply $9.88 \times 10^{7}$ molecules $\cdot s^{-1}$ of glutamine. Assuming that each molecule of glutamine produces a molecule of glutamate, a quantal content of 20 vesicles per action potential (Lorteije et al., 2009) and 7000 glutamate molecules per vesicle (Budisantoso et al., 2013), enough glutamate to sustain a continuous firing frequency of 705 $\mathrm{Hz}$, would be provided. This demonstrates that the glutamine transport capacity of the presynaptic terminal is sufficient to maintain the highest physiological levels of neurotransmission. If glutamate recycling is stopped, how long will the presynaptic supply of glutamate last? For a terminal with a presynaptic cytoplasmic volume of $477 \mu \mathrm{m}^{3}$ (Sätzler et al., 2002) that contains up to $15 \mathrm{~mm}$ glutamate (Ottersen, 1989), activity at $200 \mathrm{~Hz}$ will turn over the glutamate pool within 154 s. If glutamine transport contributes to maintaining this presynaptic glutamate pool, then inhibition by MeAIB should produce a measurable decrease in vesicular glutamate content over this time period. The reduction in mEPSC amplitude that we observe after $200 \mathrm{~Hz}$ stimulation is in line with this hypothesis. Furthermore, in quiescent calyces of Held observed after brain slicing, the presynaptic glutamate pool is not expected to be depleted; and consistent with this, MeAIB has no effect on mEPSC amplitudes or stimulated EPSCs during low-frequency stimulation. This serves as a very useful control for the lack of effect of MeAIB on other aspects of synaptic transmission, such as postsynaptic AMPA receptors or presynaptic $\mathrm{Ca}^{2+}$ channel activation. Although the calyx of Held is specialized for high-frequency transmission, other synapses are also equally reliant on rapid glutamate replenishment because of their smaller size. For example, in hippocampal CA3 to CA1 synaptic boutons of volume $0.086 \mu \mathrm{m}^{3}$, firing at $1 \mathrm{~Hz}$, with a quantal content of 0.3 (Schikorski and Stevens, 1997), the glutamate pool will be turned over in $369 \mathrm{~s}$. This indicates that these synapses must also possess continuously active glutamate recycling mechanisms to sustain neurotransmission and that the role of glutamine in glutamate recycling may be widespread.

During physiological levels of stimulation, MeAIB reduces quantal size by $26 \%$, indicating that the glutamine transport we observe is not the only mediator of synaptic glutamate recycling and that other pathways also play a significant role in replenishing the glutamate pool. In hippocampal slices, MeAIB causes a similar sized inhibition of the fEPSP slope over $5 \mathrm{~min}$, although this is reversed during prolonged $(>4 \mathrm{~h}$ ) MeAIB exposure (Kam and Nicoll, 2007), suggesting that compensation by other glutamate recycling mechanisms could occur in the long-term. It has been proposed that presynaptic terminals can directly sequester glutamate via EAAT2 transporters (Furness et al., 2008). However, despite our assay having the power to detect $<1 \mathrm{pA}$ of transporter current, glutamate did not evoke a measurable current in presynaptic terminals, even after the same electrical stimulation that induced the glutamine transport current. This indicates that glutamate is not recycled by direct presynaptic uptake via EAAT transporters, in agreement with the study of Palmer et al. (2003). Instead, glutamate is taken up into astrocytes adjacent to the calyx of Held synapse (Uwechue et al., 2012), which is advantageous from an energetic point of view as astrocytes have a greatly reduced cytoplasmic glutamate concentration compared with presynaptic terminals (Ottersen, 1989). Alternative methods of replenishing presynaptic glutamate supplies could include the presynaptic transport of TCA cycle intermediates oxoglutarate, malate or citrate by members of the sodium-carboxylate cotransporter (NaC) family (Maciejewski and Rothman, 2008). Although the complete nature of the presynaptic glutamate recycling mechanisms remains to be resolved, our data are the first to demonstrate that presynaptic glutamine transport contributes to maintaining the glutamate supply for vesicle filling and therefore influences the efficacy of excitatory neurotransmission. Furthermore, the transporter function is dynamically controlled by neuronal activity, enabling the synapse to modulate glutamate supply according to its requirements.

\section{References}

Armano S, Coco S, Bacci A, Pravettoni E, Schenk U, Verderio C, Varoqui H, Erickson JD, Matteoli M (2002) Localization and functional relevance of system A neutral amino acid transporters in cultured hippocampal neurons. J Biol Chem 277:10467-10473. CrossRef Medline

Billups B, Forsythe ID (2002) Presynaptic mitochondrial calcium sequestration influences transmission at mammalian central synapses. J Neurosci 22:5840-5847. Medline

Billups B, Wong AY, Forsythe ID (2002) Detecting synaptic connections in the medial nucleus of the trapezoid body using calcium imaging. Pflugers Arch 444:663-669. CrossRef Medline

Blot A, Billups D, Bjørkmo M, Quazi AZ, Uwechue NM, Chaudhry FA, Billups B (2009) Functional expression of two system A glutamine transporter isoforms in rat auditory brainstem neurons. Neuroscience 164: 998-1008. CrossRef Medline

Budisantoso T, Harada H, Kamasawa N, Fukazawa Y, Shigemoto R, Matsui K (2013) Evaluation of glutamate concentration transient in the synaptic cleft of the rat calyx of Held. J Physiol 591:219-239. CrossRef Medline

Chaudhry FA, Schmitz D, Reimer RJ, Larsson P, Gray AT, Nicoll R, Kavanaugh M, Edwards RH (2002) Glutamine uptake by neurons: interaction of protons with system A transporters. J Neurosci 22:62-72. Medline

Christensen HN, Oxender DL, Liang M, Vatz KA (1965) The use of $\mathrm{N}$-methylation to direct the route of mediated transport of amino acids. J Biol Chem 240:3609-3616. Medline

Deken SL, Wang D, Quick MW (2003) Plasma membrane GABA transporters reside on distinct vesicles and undergo rapid regulated recycling. J Neurosci 23:1563-1568. Medline

Furness DN, Dehnes Y, Akhtar AQ, Rossi DJ, Hamann M, Grutle NJ, Gundersen V, Holmseth S, Lehre KP, Ullensvang K, Wojewodzic M, Zhou Y, Attwell D, Danbolt NC (2008) A quantitative assessment of glutamate uptake into hippocampal synaptic terminals and astrocytes: new insights into a neuronal role for excitatory amino acid transporter 2 (EAAT2). Neuroscience 157:80-94. CrossRef Medline

Kam K, Nicoll R (2007) Excitatory synaptic transmission persists independently of the glutamate-glutamine cycle. J Neurosci 27:9192-9200. CrossRef Medline

Kopp-Scheinpflug C, Tolnai S, Malmierca MS, Rübsamen R (2008) The medial nucleus of the trapezoid body: comparative physiology. Neuroscience 154:160-170. CrossRef Medline

Lorteije JA, Rusu SI, Kushmerick C, Borst JG (2009) Reliability and precision of the mouse calyx of Held synapse. J Neurosci 29:13770-13784. CrossRef Medline

Maciejewski PK, Rothman DL (2008) Proposed cycles for functional glutamate trafficking in synaptic neurotransmission. Neurochem Int 52:809_ 825. CrossRef Medline

Ottersen OP (1989) Quantitative electron microscopic immunocytochemistry of neuroactive amino acids. Anat Embryol (Berl) 180:1-15. CrossRef

Palmer MJ, Taschenberger H, Hull C, Tremere L, von Gersdorff H (2003) Synaptic activation of presynaptic glutamate transporter currents in nerve terminals. J Neurosci 23:4831-4841. Medline

Sakaba T, Stein A, Jahn R, Neher E (2005) Distinct kinetic changes in neurotransmitter release after SNARE protein cleavage. Science 309:491-494. CrossRef Medline

Sätzler K, Söhl LF, Bollmann JH, Borst JG, Frotscher M, Sakmann B, Lübke JH (2002) Three-dimensional reconstruction of a calyx of Held and its postsynaptic principal neuron in the medial nucleus of the trapezoid body. J Neurosci 22:10567-10579. Medline 
Schikorski T, Stevens CF (1997) Quantitative ultrastructural analysis of hippocampal excitatory synapses. J Neurosci 17:5858-5867. Medline

Schneggenburger R, Forsythe ID (2006) The calyx of Held. Cell Tissue Res 326:311-337. CrossRef Medline

Sibson NR, Mason GF, Shen J, Cline GW, Herskovits AZ, Wall JE, Behar KL, Rothman DL, Shulman RG (2001) In vivo (13)C NMR measurement of neurotransmitter glutamate cycling, anaplerosis and TCA cycle flux in rat brain during [2-13C]glucose infusion. J Neurochem 76:975-989. CrossRef Medline

Sommer I, Lingenhöhl K, Friauf E (1993) Principal cells of the rat medial nucleus of the trapezoid body: an intracellular in vivo study of their physiology and morphology. Exp Brain Res 95:223-239. Medline

Tani H, Dulla CG, Huguenard JR, Reimer RJ (2010) Glutamine is required for persistent epileptiform activity in the disinhibited neocortical brain slice. J Neurosci 30:1288-1300. CrossRef Medline

Taschenberger H, von Gersdorff H (2000) Fine-tuning an auditory syn- apse for speed and fidelity: developmental changes in presynaptic waveform, EPSC kinetics, and synaptic plasticity. J Neurosci 20:91629173. Medline

Uwechue NM, Marx MC, Chevy Q, Billups B (2012) Activation of glutamate transport evokes rapid glutamine release from perisynaptic astrocytes. J Physiol 590:2317-2331. CrossRef Medline

von Kleist L, Stahlschmidt W, Bulut H, Gromova K, Puchkov D, Robertson MJ, MacGregor KA, Tomilin N, Pechstein A, Chau N, Chircop M, Sakoff J, von Kries JP, Saenger W, Kräusslich HG, Shupliakov O, Robinson PJ, McCluskey A, Haucke V (2011) Role of the clathrin terminal domain in regulating coated pit dynamics revealed by small molecule inhibition. Cell 146:471-484. CrossRef Medline

Zaia KA, Reimer RJ (2009) Synaptic vesicle protein NTT4/XT1 (SLC6A17) catalyzes $\mathrm{Na}^{+}$-coupled neutral amino acid transport. J Biol Chem 284: 8439-8448. CrossRef Medline 